\title{
Rancang Bangun Alat Titrasi Semi-Otomatis Untuk Analisa Kadar Vitamin C
}

\author{
(Design of a Semi-Automatic Titrator for Vitamin C Analysis)
}

\author{
Ahmad Zamroni ${ }^{1 *}$, Netty Maria Naibaho ${ }^{1}$, Eko Junirianto ${ }^{2}$, Hamka Nurkaya ${ }^{1}$, Rudito ${ }^{1}$, \\ Khusnul Khotimah ${ }^{1}$, Andi Lisnawati ${ }^{1}$ \\ ${ }^{1}$ Program Studi Teknologi Hasil Perkebunan, Politeknik Pertanian Negeri Samarinda, Indonesia \\ ${ }^{2}$ Program Studi Teknologi Rekayasa Perangkat Lunak, Politeknik Pertanian Negeri Samarinda, \\ Indonesia
}

${ }^{*}$ Corresponding Author: zam.ahzami@gmail.com

\begin{abstract}
ABSTRAK
Pengujian kadar vitamin $\mathrm{C}$ dalam bahan pangan adalah salah satu uji yang sering dilakukan dalam industri pangan. Diperlukan metode yang cepat, mudah, murah dan akurat untuk mengukur kadar vitamin $\mathrm{C}$ dalam bahan pangan. Tujuan penelitian ini adalah untuk merancang alat titrasi yang mudah dioperasikan dan dapat bekerja otomatis tanpa memerlukan skill yang tinggi untuk mengoperasikannya. Penelitian ini telah berhasil membuat alat titrasi semi-otomatis dengan menggunakan Arduino Uno sebagai controller utamanya. Hasil penelitian menunjukkan bahwa alat titrator semi-otomatis memiliki presisi yang cukup baik dimana koevisien variasi (KV) pembacaan alat berkisar antara 2,6 hingga 5,8\%, nilai ini hampir sebanding dengan metode titrasi manual yang memiliki KV berkisar antara 1,4 hingga 4,8\%. Meskipun memiliki presisi yang cukup baik, namun hasil akhir perhitungan kadar vitamin $\mathrm{C}$ masih berbeda jauh dibandingkan dengan perhitungan metode titrasi manual dengan selisih perhitungan mencapai lebih dari $60 \%$. Selisih nilai yang besar ini mungkin terjadi karena adanya interaksi antara iodin dengan dinding selang pompa yang menyebabkan iodin menempel di dinding selang pompa. Hal ini mengakibaktkan konsentrasi iodin yang dikeluarkan titrator menjadi lebih rendah sehingga dibutuhkan lebih banyak titran untuk mencapai titik akhir reaksi.
\end{abstract}

Kata kunci: Alat Titrasi, Analisa Vitamin C, Arduino Uno

\section{ABSTRACT}

Analysis the levels of vitamin $C$ in foods is one of the tests that is often carried out in the food industry. A fast, easy, inexpensive and accurate method is needed to measure the levels of vitamin $C$ in foods. The purpose of this research is to design a titrator that is easy to operate and can work automatically without requiring high skills to operate it. This research has succeeded in making a semi-automatic titrator using Arduino Uno as the main controller. The results showed that the semi-automatic titrator has a fairly good precision where the coefficients of variation (CV) of the tool readings ranged from 2.6 to $5.8 \%$, this value is almost comparable to the manual titration method which has a CV ranging from 1.4 to $4.8 \%$. Even though it has quite good precision, the final result of calculating vitamin $\mathrm{C}$ levels is significantly different from the calculation of the manual titration method with a calculation difference of more than $60 \%$. This large difference in value may occurs due to the interaction between iodine and the pump hose wall which causes iodine to stick to the pump hose wall. This causes the concentration of iodine released by the titrator to be lower so that more titrant is needed to reach the end point of the reaction.

Keywords: Titrator, Vitamin C Analysis, Arduino Uno

\section{PENDAHULUAN}

Vitamin C (L-asam askorbat) adalah salah satu nutrisi penting yang terkandung dalam buah dan sayur. Diantara fungsinya yang penting bagi tubuh manusia adalah sebagai antioksidan dimana vitamin C mampu menjadi pendonor elektron bagi zatzat oksidan berbahaya dalam tubuh (Devaki dan Reshma, 2017). Vitamin C juga berperan penting dalam aktivasi berbagai enzim, menangkal radikal bebas, serta menjaga sistem imun (Schlueter dan Johnston, 2011). Vitamin C dapat mencegah timbulnya beberapa penyakit diantaranya kanker, penyakit kardiovaskular, flu, degenerasi otot karena penuaan, serta katarak (Devaki dan Reshma, 2017).

Kandungan vitamin $\mathrm{C}$ yang tinggi merupakan nilai tambah bagi produk buah dan sayuran serta produk-produk turunannya. Seringkali, industri mencantumkan nilai kandungan vitamin $\mathrm{C}$ dalam produknya untuk menarik minat calon 
konsumen. Pencantuman nilai kandungan vitamin C ini juga diperlukan oleh masyarakat untuk memperkirakan berapa asupan vitamin C yang mereka penuhi dari makanan yang mereka konsumsi. Dalam industri pengolahan makanan dan minuman, analisa kandungan nutrisi produk adalah suatu kebutuhan yang terus-menerus diperlukan seiring dengan semakin meningkatnya variasi produk yang diproduksi untuk memenuhi kebutuhan pasar (Essay, 2018). Oleh karena itu diperlukan metode yang sederhana, cepat namun akurat untuk menganalisa kandungan vitamin $\mathrm{C}$ dalam suatu bahan pangan.

Kadar vitamin $\mathrm{C}$ dapat diukur dengan beberapa metode diantaranya adalah menggunakan teknik titrasi, spektrofotometri, kromatografi dan elektroforesis (Essay, 2018). Diantara metode-metode tersebut, metode titrasi iodin adalah metode yang paling sering digunakan karena metode ini relatif sederhana, murah dan dapat dikerjakan tanpa menggunakan alat laboratorium yang canggih (Techinamuti dan Rimadani, 2018).

Meski sederhana, metode iodometri memiliki kelemahan yaitu memerlukan ketelitian dan kehati-hatian dari penganalisa. Selain itu, jika sampel berjumlah banyak, faktor kelelahan bisa menurunkan konsentrasi penganalisa sehingga dapat berakibat terjadinya kesalahan pengukuran. Untuk mengatasi kelemahan metode tersebut, beberapa alat titrasi otomatis telah diproduksi oleh produsen-produsen alat laboratorium. Sayangnya, kebanyakan alat tersebut harganya relatif mahal. Oleh karena itu, beberapa peneliti telah mencoba merancang alat titrasi otomatis yang lebih sederhana dengan harga relatif murah.

Diantara alat yang telah dibuat dan telah dipublikasikan dalam artikel ilmiah diantaranya adalah alat yang dibuat oleh lka (2009) dengan prinsip dasar kesetimbangan asam-basa sebagai titik akhir reaksi. Alat tersebut dapat bekerja dengan baik dengan tingkat kesalahan sekitar 1,14\%. Selain itu, Erwanto dkk. (2019) telah membuat alat titrasi iodmetri otomatis dengan menggunakan teknologi pengolahan citra digital terhadap perubahan warna sebagai titik akhir reaksi. Sayangnya, alat tersebut memiliki nilai kesalahan yang cukup tinggi yaitu rata-rata sebesar $17,54 \%$ dibandingkan dengan pengukuran secara langsung. Hal ini disebabkan karena pengolah citra digital baru dapat mendeteksi warna biru lebih pekat pada larutan daripada pengamatan secara langsung.

Penelitian ini bertujuan untuk merancang alat titrasi semi-otomatis serta menganalisa tingkat presisi dan akurasi dari alat yang dihasilkan.

\section{BAHAN DAN METODE}

\section{A. Bahan}

Alat yang digunakan pada penelitian ini adalah sebagai berikut: Komputer, Mikrokontroller Arduino Uno R3, pompa peristaltik, Erlenmeyer, Gelas Beaker, buret.

Adapun bahan yang digunakan dalam penelitian ini adalah: asam askorbat, larutan iodin $0,01 \mathrm{~N}$, amilum $1 \%$.

\section{B. Metode Penelitian}

\section{Tahapan Penelitian}

\section{Perancangan alat}

Sebelum dimulai membuat program dan merangkai alat, terlebih dahulu akan dilakukan perancangan alat secara keseluruhan.

\section{Pemrograman mikrokontroller Arduino Uno}

Pada tahap ini, mikrokontroller akan diprogram sedemikian rupa sehingga dapat memberikan perintah kepada pompa sesuai dengan signal yang diberikan oleh perangkat android. Pemograman Arduino Uno dilakukan di komputer dengan menggunakan software Arduino IDE versi 1.8.9.

\section{Perakitan Alat}

Setelah sistem android dibuat dan mikrokontroller sudah diprogram, maka tahap selanjutnya adalah merakit alat-alat tersebut dengan alat-alat lain yang diperlukan menjadi satu kesatuan.

Setelah selesai perakitan alat, selanjutnya alat diuji apakah sudah dapat bekerja seperti yang diharapkan. Jika alat belum bekerja dengan baik maka dilakukan evaluasi kembali dan dilakukan perancangan serta pemrograman ulang hingga alat dapat bekerja dengan baik sesuai yang ada dalam rancangan awal. Diagram alir tahapan penelitian dapat dilihat di Gambar 1. 


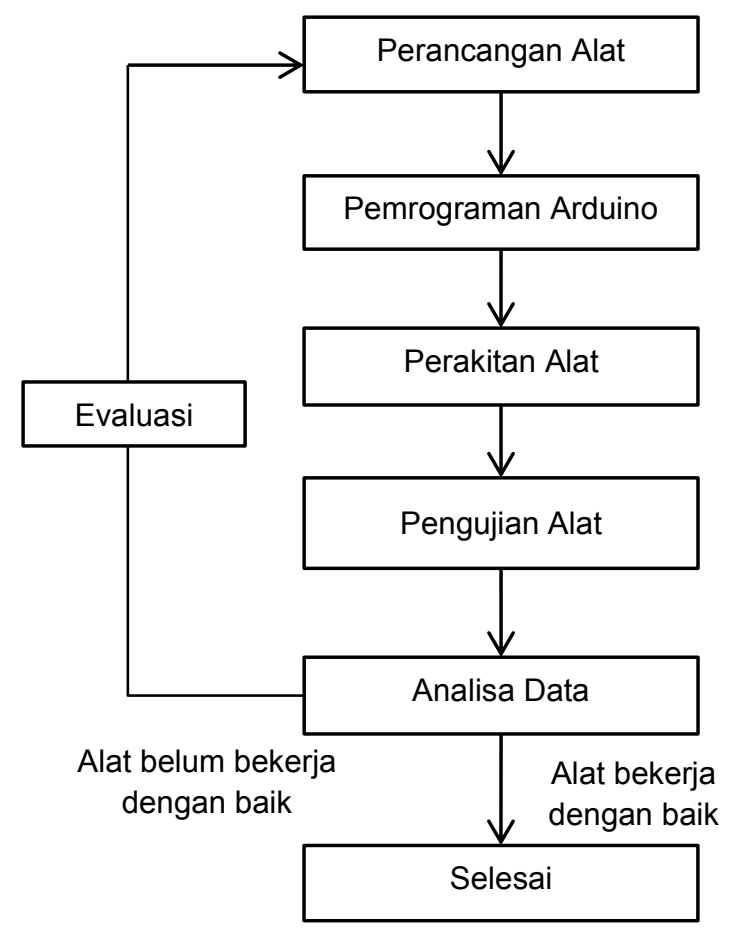

Gambar 1. Diagram Alir Tahapan Penelitian

\section{Penentuan Kadar Vitamin C}

Penentuan kadar vitamin $C$ dalam sampel dilakukan dengan menggunakan metode lodometri (Zubairu dan Fatima, 2019) dengan modifikasi. Sediakan $10 \mathrm{~g}$ sampel halus (daging buah) masing-masing dari buah ara dan markisa hutan pada labu 100 $\mathrm{mL}$ lalu ditambahkan $100 \mathrm{~mL}$ air hingga tanda batas. Tambahkan 5 tetes indikator amilum, lalu lakukan titrasi dengan iodium $\left(\mathrm{I}_{2}\right)$ $0,01 \mathrm{~N}$ sampai warna biru.

Kandungan vitamin C (mg/100gr) dapat dihitung dengan rumus:

$$
\text { Kadar Vit. } C=\frac{(\text { Vol I } 2 \times 0,88 \times \mathrm{Fp}) \times 100}{\mathrm{~W} \text { sampel }(\mathrm{g})}
$$

Keterangan:

$\mathrm{V}$ I2: Volume iodium $(\mathrm{mL})$

$0,88: 0,88 \mathrm{mg}$ Vitamin $\mathrm{C}$ setara dengan $1 \mathrm{~mL}$ larutan $120,01 \mathrm{~N}$

$\mathrm{Fp}$ : faktor pengenceran

Ws : Berat sampel $(\mathrm{g})$

\section{Analisa Data}

Untuk mengetahui ketelitian alat, pengujian dilakukan melalui dua tahap. Tahap pertama adalah menganalisa tingkat stabilitas volume lodin yang dikeluarkan alat pada setiap tetesan. Hal ini dilakukan dengan cara penimbangan tetesan cairan kemudian dikonversi menjadi volume dengan rumus:

$$
\text { Volume }(m L)=\frac{\text { berat }(g r)}{\text { massa jenis }(g r / m l)}
$$

Tahap yang kedua adalah membandingkan hasil pengujian vitamin $\mathrm{C}$ menggunakan alat dengan pengujian metode titrasi manual. Hasil pengukuran digunakan untuk mengetahui tingkat error dengan menggunakan rumus sebagai berikut:

$$
\% \text { error }=\frac{a-b}{a} \times 100 \%
$$

Dimana a adalah kadar vitamin C yang didapat dengan menggunakan alat tirasi semi-otomatis dan $b$ adalah kadar vitamin $C$ yang didapat dari perhitungan metode titrasi manual.

\section{HASIL DAN PEMBAHASAN}

Tahap awal dari penelitian ini adalah membuat rancangan rangkaian alat yang dapat mengeluarkan atau meneteskan cairan terus menerus secara otomatis. Alat tersebut dirancang sedemikian rupa sehingga dapat bekerja dengan cara sebagai berikut (Gambar 2a):

1. Sampel dengan tambahan indikator amilum ditempatkan dalam gelas beaker sedangkan larutan titran (larutan iodin) ditempatkan di wadah lain, antara sampel dan larutan titran dihubungkan dengan pompa untuk mengalirkan cairan titran ke dalam wadah sampel.

2. Ketika alat dinyalakan, maka pompa akan bekerja mengalirkan setetes demi setetes cairan titran kedalam larutan berisi sampel uji.

3. Pompa akan terus meneteskan cairan titran hingga terjadi perubahan warna yang menunjukkan titik akhir reaksi

4. Ketika terjadi perubahan warna, pengguna alat dapat memencet tombol "off" untuk menghentikan aliran cairan titran.

5. Jumlah volume cairan titran dapat diketahui dengan cara mengalikan jumlah tetesan dengan volume titran setiap tetesnya. 

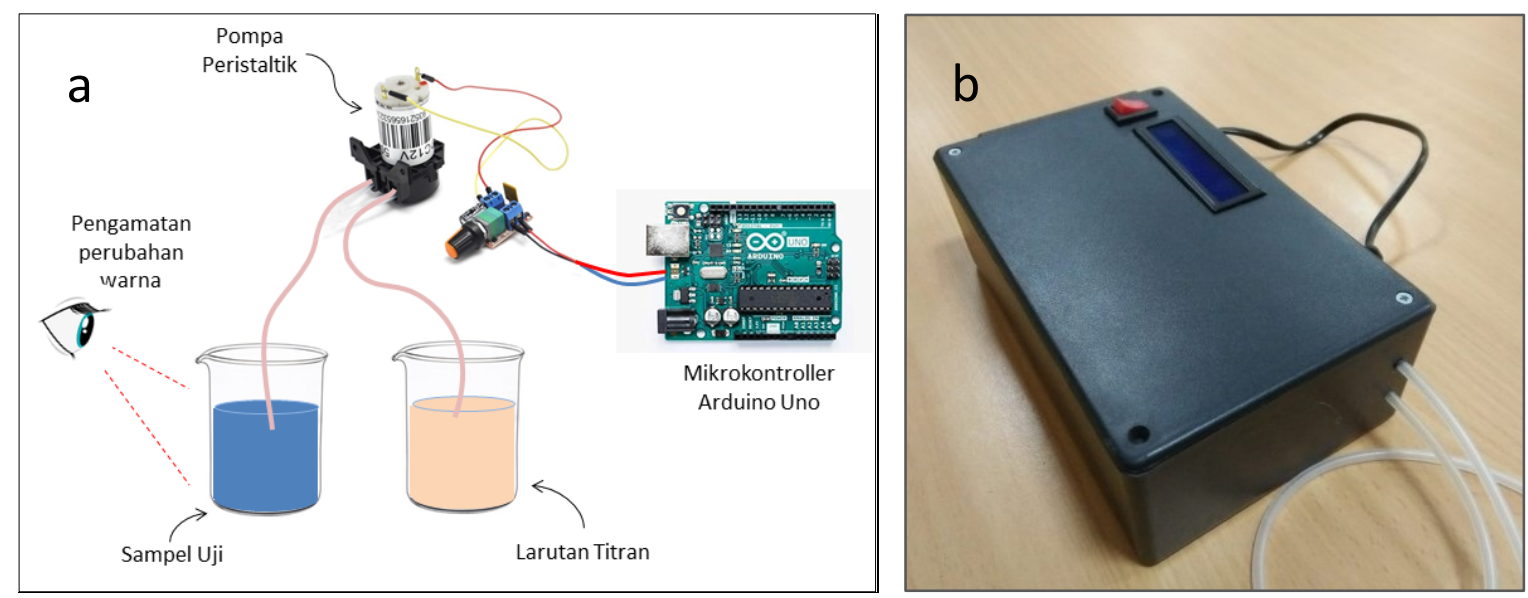

Gambar 2. Rangkaian Alat Titrasi Otomatis (a) dan Alat yang Telah Dirakit (b)

Pada tahap selanjutnya, pemrograman arduino uno dilakukan dengan tujuan untuk membuat controller yang dapat memberikan perintah nyala-mati kepada pompa peristaltik. Program arduino dirancang sedemikan rupa sehingga dapat membuat pompa menyala selama 0,2 detik dan jeda 3 detik kemudian menyala lagi dan jeda lagi, terus berulang hingga pengguna menekan tombol "stop". Hal ini diperlukan agar cairan titran yang dipompa oleh pompa peristaltik dapat keluar sedikit demi sedikit sebagaimana tetasan yang keluar dari buret pada titrasi manual.

Pada penelitian ini, alat titrasi telah berhasil dibuat sesuai dengan rancangan awal (Gambar 2b). Uji presisi volume tetesan menunjukkan bahwa alat ini mampu meneteskan cairan secara menerus dengan jumlah yang cukup stabil yaitu sebanyak $0,195 \mathrm{gr}$ dengan standar deviasi sebesar $3,7 \%$. Setelah diperhitungkan dengan nilai massa jenis iodin (Tabel 1), maka didapatkan bahwa volume tiap tetes yang dikeluarkan alat ini adalah sebanyak 0,193 mL (Tabel 2).

Tabel 1. Perhitungan Massa Jenis lodin

\begin{tabular}{cccc}
\hline ulangan & $\begin{array}{c}\text { volume } \\
(\mathrm{ml})\end{array}$ & $\begin{array}{c}\text { massa } \\
(\mathrm{gr})\end{array}$ & $\begin{array}{c}\text { massa } \\
\text { jenis } \\
(\mathrm{gr} / \mathrm{ml})\end{array}$ \\
\hline 1 & 1 & 1,002 & 1,002 \\
2 & 1 & 1,010 & 1,010 \\
3 & 1 & 1,003 & 1,003 \\
\hline \multicolumn{2}{c}{ Rata-rata } & 1,005 & 1,005 \\
\multicolumn{2}{c}{ Simpangan Baku } & 0,004 & 0,004 \\
\multicolumn{2}{c}{ Koefisien Variasi (\%) } & 0,441 & 0,441 \\
\hline
\end{tabular}

Tabel 2. Uji Presisi Volume lodin yang Dikeluarkan oleh Alat Semi-Otomatis

\begin{tabular}{|c|c|c|c|}
\hline $\begin{array}{c}\text { Jumlah } \\
\text { Tetes }\end{array}$ & Berat (gr) & $\begin{array}{l}\text { Berat per } \\
\text { tetes (gr) }\end{array}$ & $\begin{array}{c}\text { Volume } \\
\text { Per tetes } \\
(\mathrm{mL})\end{array}$ \\
\hline 10 & 1,936 & 0,194 & 0,192 \\
\hline 10 & 1,963 & 0,196 & 0,194 \\
\hline 10 & 2,043 & 0,204 & 0,202 \\
\hline 5 & 0,964 & 0,193 & 0,191 \\
\hline 5 & 0,977 & 0,195 & 0,193 \\
\hline 5 & 0,966 & 0,193 & 0,191 \\
\hline 1 & 0,195 & 0,195 & 0,193 \\
\hline 1 & 0,178 & 0,178 & 0,177 \\
\hline 1 & 0,202 & 0,202 & 0,200 \\
\hline \multicolumn{2}{|c|}{ Rata-rata } & 0,195 & 0,193 \\
\hline \multicolumn{2}{|c|}{ Simpangan Baku } & 0,007 & 0,007 \\
\hline \multicolumn{2}{|c|}{ Koefisien Variasi (\%) } & $3,7 \%$ & $3,7 \%$ \\
\hline
\end{tabular}

Pada uji kadar vitamin $\mathrm{C}$, alat titrator semi-otomatis menunjukkan presisi yang cukup baik dimana koevisien variasi (KV) pembacaan alat berkisar antara 2,6 hingga $5,8 \%$, nilai ini hampir sebanding dengan metode titrasi manual yang memiliki KV berkisar antara 1,4 hingga 4,8\% (Tabel 3). Meski hasil uji presisi volume tetesan alat menunjukkan hasil yang cukup baik, namun uji kadar vitamin $\mathrm{C}$ menggunakan alat titrasi semi-otomatis menunjukkan nilai yang berbeda jauh jika dibandingkan dengan uji vitamin $\mathrm{C}$ metode titrasi konvensional dengan selisih pehitungan 29-65\% (Tabel 3). 
Tabel 3. Perbandingan Perhitungan Kadar Vitamin C Menggunakan Metode Tritasi Manual dengan Alat Titrasi Otomatis.

\begin{tabular}{|c|c|c|c|c|c|c|}
\hline \multirow{2}{*}{ Sampel } & \multirow{2}{*}{ ulangan } & \multicolumn{2}{|c|}{ Titrasi Manual } & \multicolumn{2}{|c|}{ Alat Semi-Otomatis } & \multirow{2}{*}{$\begin{array}{c}\text { Error } \\
(\%)\end{array}$} \\
\hline & & $\begin{array}{c}\text { volume } \\
\text { iodin }(\mathrm{mL})\end{array}$ & $\begin{array}{c}\text { Kadar } \\
\text { Vitamin C }\end{array}$ & $\begin{array}{c}\text { volume } \\
\text { iodin }(\mathrm{mL})\end{array}$ & $\begin{array}{c}\text { Kadar } \\
\text { Vitamin C }\end{array}$ & \\
\hline \multirow{4}{*}{$\begin{array}{l}\text { Nutrisari } \\
\text { Jeruk }\end{array}$} & 1 & 4 & $14,06 \mathrm{mg} / \mathrm{gr}$ & 6,2 & $21,71 \mathrm{mg} / \mathrm{gr}$ & 54 \\
\hline & 2 & 4,1 & $14,41 \mathrm{mg} / \mathrm{gr}$ & 5,6 & $19,67 \mathrm{mg} / \mathrm{gr}$ & 37 \\
\hline & 3 & 4 & $14,06 \mathrm{mg} / \mathrm{gr}$ & 5,6 & $19,67 \mathrm{mg} / \mathrm{gr}$ & 40 \\
\hline & $\mathrm{KV}(\%)$ & $1,4 \%$ & $1,4 \%$ & $5,8 \%$ & $5,8 \%$ & \\
\hline \multirow{4}{*}{$\begin{array}{l}\text { Nutrisari } \\
\text { Sayur }\end{array}$} & 1 & 3,3 & $11,60 \mathrm{mg} / \mathrm{gr}$ & 4,2 & $14,92 \mathrm{mg} / \mathrm{gr}$ & 29 \\
\hline & 2 & 3 & $10,55 \mathrm{mg} / \mathrm{gr}$ & 4,4 & $15,60 \mathrm{mg} / \mathrm{gr}$ & 48 \\
\hline & 3 & 3,2 & $11,25 \mathrm{mg} / \mathrm{gr}$ & 4,4 & $15,60 \mathrm{mg} / \mathrm{gr}$ & 39 \\
\hline & $\mathrm{KV}(\%)$ & $4,8 \%$ & $4,8 \%$ & $2,6 \%$ & $2,6 \%$ & \\
\hline \multirow{4}{*}{$\begin{array}{l}\text { Ascorbic } \\
\text { Acid }\end{array}$} & 1 & 4,4 & $77 \mathrm{mg} / 100 \mathrm{~mL}$ & 6,6 & $115 \mathrm{mg} / 100 \mathrm{~mL}$ & 49 \\
\hline & 2 & 4,2 & $742 \mathrm{mg} / 100 \mathrm{~mL}$ & 6,9 & $122 \mathrm{mg} / 100 \mathrm{~mL}$ & 65 \\
\hline & 3 & 4,4 & $77 \mathrm{mg} / 100 \mathrm{~mL}$ & 6,4 & $112 \mathrm{mg} / 100 \mathrm{~mL}$ & 45 \\
\hline & $\mathrm{KV}(\%)$ & $2,7 \%$ & $2,7 \%$ & $4,5 \%$ & $4,5 \%$ & \\
\hline
\end{tabular}

Dari tabel diatas, dapat dilihat bahwa jumlah iodin yang diperlukan untuk mencapai titik akhir reaksi pada sistem alat semiotomatis adalah selalu lebih besar dibandingkan titrasi konvensional. Hal ini mungkin disebabkan karena adanya interaksi antara iodin dengan selang yang ada pada alat titrasi semi-otomatis. lodin bersifat nonpolar, begitu juga bahan pembuat selang yang terbuat dari silikon. Antara iodin dan selang kemudian terjadi interaksi hidrofobik sehingga iodin akan menempel di dinding selang. Hal ini menyebabkan konsentrasi iodin yang keluar dari alat akan berkurang meskpun jumlah volumenya tetap. Dengan demikian, diperlukan lebih banyak iodin untuk mencapai titik akhir reaksi pada sistem alat titrasi semi-otomatis.

\section{KESIMPULAN}

Penelitian ini telah menghasilkan alat titrator dengan presisi yang cukup bagus dilihat dari kemampuannya meneteskan cairan titran. Akan tetapi, hasil akhir perhitungan kadar vitamin $\mathrm{C}$ masih berbeda jauh dibandingkan dengan perhitungan metode titrasi manual. Perbedaan nilai tersebut mungkin disebabkan oleh adanya interaksi molekuler antara iodin dan dinding selang yang ada pada alat titrasi semiotomatis. Oleh karena itu, diperlukan penelitian lebih lanjut untuk meningkatkan akurasi alat tersebut.

\section{UCAPAN TERIMA KASIH}

Penulis mengucapkan terimakasih kepada Politeknik Pertanian Negeri Samarinda yang telah mendanai penelitian ini melalui sumber dana PNBP Politeknik Pertanian Negeri Samarinda Tahun Anggaran 2020.

\section{DAFTAR PUSTAKA}

Devaki, S.J. and Reshma, L.R. 2017. Vitamin C: Sources, Functions, Sensing and Analysis. Intechopen. DOI: 10.5772/intechopen.70162

Erwanto, D., Utomo, Y.B., Fiolana, F.A., Yahya, M. 2019. Pengolahan Citra Digital untuk Menentukan Kadar Asam Askorbat pada Buah dengan Metode Titrasi lodimetri. Jurnal IImiah Multitek Indonesia 12(2): 73-84. 
Essay, UK. 2018. Existing analytical methods for the determination of vitamin $C$ in fruits and beverages. https://ukdiss.com/examples/0141526. php?vref=1

Ika, D. 2009. Alat Otomatisasi Pengukur Kadar Vitamin C Dengan Metode Titrasi Asam Basa. Jurnal Neutrino 1(2): 163-178.

Schlueter, A.K. dan Johnston, C.S. 2011. Vitamin C: Overview and Update. Journal of Evidence-Based Complementary \& Alternative Medicine 16(1): 49-57

Techinamuti, N. dan Rimadani, P. 2018. Review: Metode Analisis Kadar Vitamin C. Farmaka 16(2): 309-315

Zubairu, M.S. dan Fatima. M. 2019. Comparative Analysis of Vitamin C (ascorbic acid) in Fresh and Packaged Fruit Juices by lodometric Titration. International Journal of Food Nutrition and Safety 10 (1): 26-41 